Notes and Comments

doi: 10.4183/aeb.2013.489

\title{
CONTRIBUTION OF GENES TO THE CHANGES ON BODY COMPOSITION COMPONENTS: A TWO-YEAR LONGITUDINAL STUDY IN A SMALL COHORT OF TWINS
}

\author{
A.D. Tarnoki ${ }^{1 *}$, D.L. Tarnoki ${ }^{1}$, A.A. Molnar ${ }^{2,3}$, V. Berczi ${ }^{1}$, Z. Garami ${ }^{4}$, K. Karlinger ${ }^{1}$ \\ ${ }^{I}$ Semmelweis University - Department of Radiology and Oncotherapy, ${ }^{2}$ Military \\ Hospital - Department of Cardiology, ${ }^{3}$ Research Group for Inflammation Biology \\ and Immunogenomics of Hungarian Academy of Sciences and Semmelweis \\ University, Budapest, Hungary, ${ }^{4}$ The Methodist Hospital - DeBakey Heart \& \\ Vascular Center, Houston, Texas, United States of America
}

\begin{abstract}
Context. High heritability of determinants. Negative associations were observed with regard to the two-year change in waist and hip circumferences, suggesting body composition variables is well-known, however, longitudinal effect of genes is still unclear.

Objective. The aim of this study was to investigate the pattern of longitudinal changes in anthropometric variables in a small cohort of twins.

Design. Longitudinal classical twin study, performed in 2009 and in 2011 on the same twin pairs.

Subjects and Methods. Eighteen healthy adult Hungarian twin pairs (13 monozygotic [MZ], 5 dizygotic [DZ]; mean age $54.0 \pm 15.2$ years; average body mass index $24.4 \pm 5.4 \mathrm{~kg} / \mathrm{m}^{2}$ in 2009 and $25.1 \pm 4.7$ $\mathrm{kg} / \mathrm{m}^{2}$ in 2011, respectively) recruited from the Hungarian Twin Registry underwent bioimpedance analysis (OMRON).

Results. Significant, higher positive intrapair correlations were detected in the longitudinal change in weight $(\mathrm{p}<0.05)$, body fat mass $(\mathrm{p}<0.01)$, non-fat mass $(\mathrm{p}<0.01)$, and body mass index $(\mathrm{p}<0.01)$ in $\mathrm{MZ}$ compared to DZ twins, suggesting the possibility of longitudinal genetic the longitudinal role of environmental factors in these phenotypes.

Conclusions. The findings of the present human twin study suggest that weight, body fat mass, non-fat mass, and body mass index are determined genetically and longer exposure to pathologic environmental factors is necessary to elicit alterations in the regulation of these parameters. Longer-term confirmation in a larger sample is required to confirm these results.

Key words: genetics, body mass index, body fat mass, environment, heritability.

\section{INTRODUCTION}

Obesity is a complex condition of excessive fat accumulation linked to a variety of genetic and non-genetic risk factors. Obesity has reached epidemic proportions worldwide with more than

*Correspondence to: Adam Domonkos Tarnoki MD, Semmelweis University, Department of Radiology and Oncotherapy, 78/A Ulloi Street, Budapest, 1082, Hungary, E-mail: tarnoki2@ gmail.com
\end{abstract}

Acta Endocrinologica (Buc), vol. IX, no. 3, p. 489-498, 2013 


\section{A.D. Tarnoki et al.}

one billion overweight adults, of which at least 300 million are clinically obese (1). Various epidemiological studies based on family, adoption, and twin relations indicate that genetic influences contribute substantially to variation in obesity $(2,3)$. Multiple twin studies have shown that a sizeable proportion of body weight, waist and hip circumference, and body mass index (BMI) variances are due to genetic variance, which usually ranges between $60 \%$ and $80 \%$ (4-7). Common obesity is polygenic, involving complex genegene and gene-environment interactions that contribute to multi-factorial obese phenotypes (8). Collectively, these findings suggest that gene-environment interactions in particular may increase the risk of obesity among those who are genetically predisposed to weight gain.

BMI is a simple but quantitative anthropometric measure of body fat based on height and weight that applies to adult men and women. A Danish study found that BMI is a good reflection of body fat (9). Several studies have investigated the interplay of genetic and environmental influences on anthropometric parameters related to obesity by studying twin cohorts. Two longitudinal studies indicated the stable heritability of BMI with follow-up times of 28 and 6 years, respectively (10, 11). However, some studies reported decreasing heritability across age (12), and yet others reported increasing values (13). To accept the theory of age-induced effects on heritability, one must assume that different genes become activated at different ages even if heritability does not change substantially. As recently reported, genetic effects may account for a BMI heritability of $75 \%$ in men and $71 \%$ in women (14). A small German study consisting of 30 twins investigated several body composition traits by tetrapolar bioelectrical impedance analysis and found that genetic factors amounted to a variance of $65-82 \%$ (15). A large Danish study found a heritability of 58-63\% for BMI, 59-63\% for body fat percentage, $48-61 \%$ for waist circumference, and 52-58\% for hip circumference (16).

Beyond BMI, little is known as to whether heritable factors may contribute to the pattern of change in body composition parameters during a lifetime. Therefore, the genetics of body composition change remains an important unresolved question (17). To the best of our knowledge, no longitudinal study has investigated the role of genetic effects on aging-related changes in body composition. Therefore, our aim was to investigate the pattern of longitudinal changes in the provided phenotypes of body composition components, assuming that not only the measured traits, but also their pattern of longitudinal change, could be genetically determined.

\section{MATERIALS AND METHODS}

\section{Subjects and study design}

Thirty-six healthy Hungarian adult twin subjects (18 twin pairs; 13 monozygotic [MZ] and 5 /four same-sex and one opposite-sex/ dizygotic [DZ] pairs; 3 males and 33 females; mean age $54.0 \pm 15.2$ years) who were participants of the International Twin Study 2009 were tested at the festival in 2009 and again two years later in 2011 recruited from the 


\section{Longitudinal twin study on body composition}

Hungarian Twin Registry (18). In 2009, 160 Hungarian twin pairs were measured during two Hungarian twin festivals (Szigethalom, Ágfalva) or at two large hospitals in Budapest. The same 160 twin pairs were invited to participate in the follow-up study during the same twin festivals in Szigethalom and Ágfalva in July, 2011. Of the 160 twin pairs, only 19 twin pairs decided to participate again, mainly due to bad weather conditions on the days of the twin festivals. Exclusion criteria included pregnancy, foreseeable lack of compliance with test procedures, and patients having pacemakers. In the absence of genotyping and in order to maximize the accuracy of zygosity classification, we used a multiple-choice, self-reported questionnaire. Zygosity was assigned according to a seven-part, self-reported response (19). Participants were asked to fill out a questionnaire in order to report any clinical symptoms, a complete medical history of the previous two years, and any medication being taken for cardiovascular conditions. All study subjects gave informed consent prior to entering the study, which was conducted in full compliance with regulations of the Ethical Committee of Semmelweis University and thus meets the standards of the Declaration of Helsinki. Assessment of body composition Body composition was determined by a clinically validated, portable body consistency monitor (OMRON BF500, Omron Healthcare Ltd., Kyoto, Japan) using bioelectrical impedance analysis (20). The monitor sends a weak electrical current of 50 $\mathrm{kHz}$ and less than $500 \mu \mathrm{A}$ through the subject's body to determine the amount of fat tissue. Muscles, blood vessels, and bones with high water content conduct electricity easily, while body fat has little electric conductivity. During the course of day, body water tends to gradually shift to the lower limbs making the ratio of water between the upper and lower body different in the morning and evening. Accordingly, the body's electrical impedance varies during the day. Use of electrodes for both hands and feet may reduce the influence of fluctuations on measured values. To further improve consistency, measurements were taken in the late morning hours and in the afternoon. To avoid electromagnetic interference, subjects with pacemakers were excluded from the study. Subjects were asked not to eat 1 hour, not to drink coffee and not to smoke for 3 hours, and not to drink alcohol for 10 hours before the exam. Under the guidance of a trained assistant, current height, age, and gender information were entered into the monitor in order to generate results. The subjects were instructed to stand on the monitor barefooted with straight knees and back, looking straight ahead with horizontally raised arms and extended elbows. The extended arms were at a $90^{\circ}$ angle to the subject's body until the BMI, total body fat, and fat-free mass were calculated. Body fat percentage refers to the amount of body fat mass as a fraction of total body weight, and was calculated as follows:

Body fat percentage $(\%)=[$ Body fat mass $(\mathrm{kg}) /$ Body weight $(\mathrm{kg})] \times 100$

Fat-free mass was calculated as: $100 \%$ - body fat percentage (\%). 


\section{A.D. Tarnoki et al.}

Waist and hip circumferences were measured by placing a measuring tape in a horizontal plane mid-way between the top of the iliac bone and the bottom of the rib cage, and at hip level, respectively. The same device was used in both years by the same personnel.

\section{Statistical analysis}

A descriptive analysis (mean, standard deviation, and percentage for categorical variables) for the investigated body composition parameters was conducted by SPSS Statistics 17. $P$ values less than 0.05 were considered significant between $\mathrm{MZ}$ and DZ twin groups using independent-sample t-tests.

First, the intrasubject differences of body composition parameters during the two-year follow-up period were calculated for each $\mathrm{MZ}$ and $\mathrm{DZ}$ twin subjects. Next, the intrapair changes during the two-year follow-up period were calculated for both zygosity groups by extracting the intrasubject difference for twin B from the same value for twin A. The average values in $\mathrm{MZ}$ and DZ groups were calculated separately and compared by independent-sample t-test. If the change in two-year intrapair similarity for a phenotype is smaller in MZ than DZ pairs, there is evidence for genetic influence. Finally, the ageadjusted intraclass (partial) correlation of intrapair changes in body composition parameters during the two-year followup period was calculated for $\mathrm{MZ}$ and DZ twins. Higher intraclass correlation in MZ twins compared to DZ indicates a genetic effect.

\section{RESULTS}

\section{Subject characteristics}

Baseline characteristics of the study subjects according to zygosity are presented in Table 1. Regardless of

Table 1. Baseline characteristics of study subjects

\begin{tabular}{|c|c|c|c|}
\hline & $\begin{array}{c}\text { Total } \\
(\mathbf{n}=\mathbf{3 6})^{*}\end{array}$ & $\begin{array}{c}\text { Monozygotic } \\
(\mathbf{n}=26)^{*}\end{array}$ & $\begin{array}{c}\text { Dizygotic } \\
(\mathrm{n}=10)^{*}\end{array}$ \\
\hline Male:female (n) & $3: 33$ & $2: 24$ & $1: 9$ \\
\hline Age (2009), years ${ }^{\ddagger}$ & $54.0 \pm 15.2$ & $50.0 \pm 15.0$ & $64.4 \pm 10.3^{\dagger}$ \\
\hline weight (2009), $\mathrm{kg}^{\ddagger}$ & $66.8 \pm 17.1$ & $64.1 \pm 17.6$ & $73.7 \pm 14.5$ \\
\hline weight (2011), $\mathrm{kg}^{\ddagger}$ & $68.3 \pm 14.7$ & $66.3 \pm 14.6$ & $73.5 \pm 14.3$ \\
\hline waist circumference (2009), $\mathrm{cm}^{\ddagger}$ & $88.4 \pm 13.2$ & $86.1 \pm 12.6$ & $93.8 \pm 13.7^{\$}$ \\
\hline waist circumference (2011), $\mathrm{cm}^{\ddagger}$ & $83.8 \pm 12.8$ & $80.2 \pm 12.2$ & $93.2 \pm 9.2$ \\
\hline hip circumference (2009), cm & $98.6 \pm 12.8$ & $96.5 \pm 93.6$ & $103.5 \pm 12.9$ \\
\hline hip circumference (2011), $\mathrm{cm}^{\ddagger}$ & $96.8 \pm 13.3$ & $93.6 \pm 13.2$ & $105.3 \pm 10.0^{\S}$ \\
\hline body fat mass (2009), $\%^{\ddagger}$ & $30.6 \pm 11.1$ & $28.2 \pm 10.6$ & $36.4 \pm 10.2^{\S}$ \\
\hline body fat mass (2011), \% & $33.4 \pm 8.9$ & $32.1 \pm 8.3$ & $36.8 \pm 10.1$ \\
\hline non-fat mass (2009), \% & $69.4 \pm 11.1$ & $71.8 \pm 10.6$ & $63.6 \pm 10.2^{\S}$ \\
\hline non-fat mass (2011), $\%^{\ddagger}$ & $66.6 \pm 8.9$ & $67.9 \pm 8.3$ & $63.2 \pm 10.1$ \\
\hline BMI (2009), kg/m & $24.4 \pm 5.4$ & $23.2 \pm 5.1$ & $27.4 \pm 5.2^{\S}$ \\
\hline $\operatorname{BMI}(2011), \mathrm{kg} / \mathrm{m}^{2 \ddagger}$ & $25.1 \pm 4.7$ & $24.2 \pm 4.3$ & $27.3 \pm 5.2$ \\
\hline
\end{tabular}

${ }^{*}$ number of twin pairs; łmean \pm standard deviation; $\S p<0.05 ; \dagger p<0.01, \$ p<0.005$

$\mathrm{BMI}$, body mass index 


\section{Longitudinal twin study on body composition}

zygosity, female gender dominated in both groups. Dizygotic participants were significantly older than MZ participants $(p<0.001)$. Some significant differences were observed between baseline anthropometric parameters of $\mathrm{MZ}$ and DZ twins $(\mathrm{p}<0.05$ or $\mathrm{p}<0.005)$.

Changes in body composition parameters over time

No significant intrasubject changes were observed in body composition parameters of $\mathrm{MZ}$ and DZ twin subjects during the two-year follow-up period (Table 2). Borderline significance was observed regarding the change in body fat mass and nonfat mass between $\mathrm{MZ}$ and $\mathrm{DZ}$ cohorts $(p=0.052)$. In addition, changes in the absolute values of the measured body composition parameters were calculated for each twin pair. No significant differences were observed in the average intrapair change in body composition parameters within $\mathrm{MZ}$ and DZ twin pairs during the two-year follow-up period (Table 3).

\section{Concordance in the direction of} intrapair change in body composition parameters

Concordance of intrapair change examined similarities in the direction of change among twin pairs. There were significantly more concordant pairs in the $\mathrm{MZ}$ versus $\mathrm{DZ}$ cohort with regards to the direction of change in weight, body mass, non-fat mass, and BMI.

Table 2. Intrasubject changes in body composition parameters during the two-year follow-up period

\begin{tabular}{lcc}
\hline & $\begin{array}{c}\text { Monozygotic* } \\
(\mathbf{n = 2 6})^{\ddagger}\end{array}$ & $\begin{array}{c}\text { Dizygotic* } \\
(\mathbf{n = 1 0})^{\ddagger}\end{array}$ \\
\hline weight, $\mathrm{kg}$ & $2.23 \pm 5.5$ & $-0.27 \pm 2.5$ \\
waist circumference, cm & $-4.44 \pm 5.8$ & $-0.60 \pm 8.4$ \\
hip circumference, $\mathrm{cm}$ & $-1.29 \pm 8.1$ & $1.8 \pm 3.9$ \\
body fat mass, \% & $4.98 \pm 6.9^{\S}$ & $0.44 \pm 2.6$ \\
non-fat mass, \% & $-4.98 \pm 6.9^{\S}$ & $-0.44 \pm 2.6$ \\
BMI, $\mathrm{kg} / \mathrm{m}^{2}$ & $1.03 \pm 2.7$ & $-0.09 \pm 0.9$ \\
\hline
\end{tabular}

*mean \pm standard deviation; ¥number of twin subjects; $\S p=0.052$

BMI, body mass index

Table 3. Intrapair changes in body composition parameters during the two-year follow-up period

\begin{tabular}{lcc}
\hline & $\begin{array}{c}\text { Monozygotic** } \\
(\mathbf{n = 1 3})^{\ddagger}\end{array}$ & $\begin{array}{c}\text { Dizygotic* } \\
(\mathbf{n = 5})^{\ddagger}\end{array}$ \\
\hline weight, kg & $2.61 \pm 4.2$ & $4.26 \pm 2.1$ \\
waist circumference, cm & $5.29 \pm 3.0$ & $4.80 \pm 4.5$ \\
hip circumference, cm & $8.75 \pm 7.1$ & $2.80 \pm 2.5$ \\
body fat mass, \% & $3.26 \pm 3.1$ & $2.92 \pm 4.2$ \\
non-fat mass, \% & $3.26 \pm 3.1$ & $2.92 \pm 4.2$ \\
BMI, kg/m ${ }^{2}$ & $1.39 \pm 2.1$ & $1.31 \pm 0.6$ \\
\hline
\end{tabular}

*mean \pm standard deviation; ¥number of twin pairs BMI, body mass index 


\section{A.D. Tarnoki et al.}

There were also concordant MZ twin pairs with regards to changes in waist and hip circumferences; however, the relationship was not significant (Table 4). Finally, the age-adjusted intraclass (partial) correlation of intrapair changes in body composition parameters (weight, body fat, non-fat mass and BMI) was higher in MZ twins compared to DZ twins during the two-year follow-up period, indicating a genetic effect (Table 5).

\section{DISCUSSION}

Genetic studies have demonstrated that the relative contribution of genes to a phenotype usually decreases over time, resulting in lower estimates of heritability. This decrease is due, in part, to the accumulation of various environmental factors that tend to increase the total phenotypic variance while maintaining a constant genetic variance. On the other hand, different sets of genes could be contributing to the variance of a phenotype over time. The data obtained from twin studies represent an opportunity to investigate these hypotheses. By comparing identical twins (who share $100 \%$ of their genes) with non-identical twins (who share $50 \%$ of their genes), twin studies

Table 4. Concordance in the direction of intrapair changes in body composition parameters during the two-year follow-up period

\begin{tabular}{lcc}
\hline & $\begin{array}{c}\text { Monozygotic } \\
(\mathbf{n}=13)^{*}\end{array}$ & $\begin{array}{c}\text { Dizygotic } \\
(\mathbf{n = 5})^{*}\end{array}$ \\
\hline weight, $\mathrm{kg}$ & $7(26.9)^{\ddagger}$ & $0(0.0)$ \\
waist circumference, cm & $9(34.6)$ & $5(50.0)$ \\
hip circumference, cm & $7(26.9)$ & $5(50.0)$ \\
body fat mass, \% & $10(38.5)^{\S}$ & $1(10.0)$ \\
non-fat mass, \% & $10(38.5)^{\S}$ & $1(10.0)$ \\
BMI, kg/m & $9(34.6)^{\S}$ & $0(0.0)$ \\
\hline
\end{tabular}

*number of twin pairs (\% of concordant answers in parentheses); $¥ p<0.05 ; § p<0.01$

$\mathrm{BMI}$, body mass index

Table 5. Age-adjusted intraclass (partial) correlation of intrapair changes in body composition parameters during the two-year follow-up period

\begin{tabular}{lcc}
\hline & $\begin{array}{c}\text { Monozygotic } \\
(\mathbf{n = 1 3})^{*}\end{array}$ & $\begin{array}{c}\text { Dizygotic } \\
(\mathbf{n = 5})^{*}\end{array}$ \\
\hline$\Delta$ weight & $0.670^{\ddagger}$ & $-0.990^{\ddagger}$ \\
$\Delta$ waist circumference & $0.660^{\ddagger}$ & $0.974^{\ddagger}$ \\
$\Delta$ hip circumference & 0.109 & 0.532 \\
$\Delta$ body fat mass & $0.658^{\ddagger}$ & -0.427 \\
$\Delta$ non-fat mass & $0.658^{\ddagger}$ & -0.427 \\
$\Delta$ BMI & $0.753^{\S}$ & $-0.965^{\ddagger}$ \\
\hline
\end{tabular}

*number of twin pairs; $¥ p<0.05 ; \S p<0.01$

$\mathrm{BMI}$, body mass index 


\section{Longitudinal twin study on body composition}

produce information on the relative contribution of genes and environment. Genetic studies using the twin design are based upon the assumption that twins are representative of the general population for the outcomes being studied. To our knowledge, this is the first longitudinal twin study investigating the relative contribution of genetic factors to changes in body composition variables, assuming that not only the measured traits, but also their pattern of longitudinal change, could be genetically determined. We chose these dynamic phenotypes because of their known tendency to increase during adult lifespan and they can be comprehensively evaluated by repeated measurements over the span of the study. Our analysis is based on data obtained from a cohort of adult twin pairs during a short time interval. We report that there was a suspected genetic influence during the two-year change in weight, body fat mass, non-fat mass, and BMI, but no significant influence on waist and hip circumferences.

During the two-year followup period, weight, BMI, and body fat slightly increased overall, while nonfat mass, waist circumference, and hip circumference decreased (Table 1). Since two previous longitudinal studies indicated stable heritability of BMI $(10,11)$ and there is strong evidence for the high heritability of body weight, waist and hip circumference, and BMI variances (4-7), we hypothesized that the heritability of these parameters would remain stable. Our short-term results seem to confirm stable heritability, not only for BMI, but also for other body composition variables. Although we could not calculate exact heritability using the classical A-C-E model due to our sample size, the significantly higher concordance rate for the direction of change in body composition as well as the higher, significant intraclass correlation of $\mathrm{MZ}$ twins compared to DZ twins suggests the role of genetic factors. The short-term change in waist and hip circumferences showed no genetic influence, which may be associated with the increasing role of epigenetic factors. To date, no other longitudinal study has investigated the role of changes in the genetic determination of waist and hip circumferences by age. According to our short-term findings, genetic determination tends to decrease by aging for these phenotypes. However, we could not confirm the exact extent of change in heritability (whether it increases or decreases) because of the lack of A-C-E analysis due to sample size.

Adverse body composition is associated with co-morbidities such as type 2 diabetes mellitus and other metabolic abnormalities, respiratory disturbances, cardiovascular conditions, and increased risk for cancer, particularly malignancies of the digestive system (2124). Based on the longitudinal genetic determination of most of the body composition variables as corroborated by our findings, screening for these comorbidities must be considered. Due to the possible increasing longitudinal role of environmental factors in waist and hip circumferences, the incidence of comorbidities may occur with increasing waist and hip circumferences. It has to be taken into account that obesity-associated adverse health effects may not develop 


\section{A.D. Tarnoki et al.}

in 'metabolically benign' obesity (i.e., obesity unaccompanied by hypertension, dyslipidemia, and diabetes) when body fat exerts a beneficial effect by soaking up toxic fatty acids and protecting from deleterious effects primarily associated with visceral obesity (25). However, women with metabolically benign overweight or obesity were reported to have a greater subclinical cardiovascular disease burden compared to normal weight women (26).

Our study has several limitations. Obvious limitations are the relatively small sample size (especially of the dizygotic pairs) and short observation period which limited a concrete conclusion of gene environment interactions. A major strength of the present study is that the tests were performed by the same trained researchers using the same instrument and novel findings are presented.

In conclusion, our study suggests a genetic influence during the two-year change in weight, body fat mass, non-fat mass, and BMI. These results indicate the possibility of shortterm longitudinal genetic determinants in these phenotypes. In contrast, shortterm longitudinal roles of environmental factors can be suspected for changes in waist and hip circumferences. Accordingly, our findings underscore the importance of lifestyle in the long-term, primary prevention of increased waist and hip circumferences. Large sample sizes and longer longitudinal observation periods are warranted for confirmation of our findings. The phenotypes derived from longitudinal data could then be used to find the locations of genes involved in long-term regulation of the investigated anthropometric variables, since those long-term regulatory genes may play key roles in common diseases with late onset.

\section{Conflict of interest}

We declare that there is no conflict of interest.

\section{Acknowledgements}

The authors would like to disclose the financial and technical support provided by Medexpert Ltd. in this study. The help of the organizers of both twin festivals is gratefully acknowledged.

\section{References}

1. Nguyen DM, El-Serag HB. The epidemiology of obesity. Gastroenterol Clin North Am 2010; 39(1):1-7.

2. Allison DB, Kaprio J, Korkeila M, Koskenvuo M, Neale MC, Hayakawa K. The heritability of body mass index among an international sample of monozygotic twins reared apart. Int $\mathrm{J}$ Obes Relat Metab Disord 1996; 20(6):501-506.

3. Haworth CM, Plomin R, Carnell S, Wardle J. Childhood obesity: genetic and environmental overlap with normal-range BMI. Obesity (Silver Spring) 2008; 168(7):1585-1590.

4. Jermendy G, Horváth T, Littvay L, Steinbach R, Jermendy AL, Tárnoki AD, Tárnoki DL, Métneki J, Osztovits J. Effect of genetic and environmental influences on cardiometabolic risk factors: a twin study. Cardiovasc Diabetol 2011;10: 96.

5. Jermendy G, Littvay L, Steinbach R, Jermendy A, Tárnoki A, Tárnoki D, Métneki J, Osztovits J. Heritability of the risk factors characteristic for the metabolic syndrome: a twin study. Orv Hetil 2011; 152(32):1265-1271.

6. Wu T, Snieder H, Li L, Cao W, Zhan S, Lv J, Gao W, Wang X, Ding X, Hu Y. Genetic and environmental influences on blood pressure and body mass index in Han Chinese: a twin study. Hypertens Res 2011; 34(2):173-179.

7. Tarnoki AD, Tarnoki DL, Medda E, Cotichini R, Stazi MA, Fagnani C, Nisticò L, Lucatelli P, Boatta E, Zini C, Fanelli F, Baracchini C, Meneghetti G, Schillaci G, Osztovits J, Jermendy G, Kiss RG, Préda I, Karlinger K, Lannert A, Metneki J, Molnar AA, Garami Z, Berczi V, Halasz 


\section{Longitudinal twin study on body composition}

I, Baffy G. Bioimpedance analysis of body composition in an international twin cohort. In Press: Obes Res Clin Pract (2012), http://dx.doi. org/10.1016/j.orcp.2012.09.001

8. Hetherington MM, Cecil JE. Gene-environment interactions in obesity. Forum Nutr 2010; 63:195-203.

9. Schousboe K, Willemsen G, Kyvik KO, Mortensen J, Boomsma DI, Cornes BK, Davis CJ, Fagnani C, Hjelmborg J, Kaprio J, De Lange M, Luciano M, Martin NG, Pedersen N, Pietiläinen KH, Rissanen A, Saarni S, Sørensen TI, Van Baal GC, Harris JR. Sex differences in heritability of BMI: a comparative study of results from twin studies in eight countries. Twin Res 2003; 6(5):409-421.

10. Fabsitz RR, Carmelli D, Hewitt JK. Evidence for independent genetic influences on obesity in middle age. Int J Obes Relat Metab Disord 1992; 16(9):657-666.

11. Korkeila M, Kaprio J, Rissanen A, Koskenvuo M. Consistency and change of body mass index and weight. A study on 5967 adult Finnish twin pairs. Int J Obes Relat Metab Disord 1995; 19(5):310-317.

12. Carmichael CM, McGue M. A cross-sectional examination of height, weight, and body mass index in adult twins. J Gerontol A Biol Sci Med Sci 1995; 50(4):B237-244.

13. Herskind AM, McGue M, Sorensen TI, Harvald B. Sex and age specific assessment of genetic and environmental influences on body mass index in twins. Int $\mathrm{J}$ Obes Relat Metab Disord 1996; 20(2):106-113.

14. Lehtovirta M, Pietiläinen KH, Levälahti E, Heikkilä K, Groop L, Silventoinen K, Koskenvuo M, Kaprio J. Evidence that BMI and type 2 diabetes share only a minor fraction of genetic variance: a follow-up study of 23,585 monozygotic and dizygotic twins from the Finnish Twin Cohort Study. Diabetologia 2010; 53(7):1314-1321.

15. Hanisch D, Dittmar M, Hohler T, Alt KW. Contribution of genetic and environmental factors to variation in body compartments-a twin study in adults. Anthropol Anz 2004; 62(1):51-60.

16. Schousboe K, Visscher PM, Erbas B, Kyvik KO, Hopper JL, Henriksen JE, Heitmann BL, Sørensen TI. Twin study of genetic and environmental influences on adult body size, shape, and composition. Int J Obes Relat Metab Disord 2004; 28(1):39-48.

17. Silventoinen K, Kaprio J. Genetics of tracking of body mass index from birth to late middle age: evidence from twin and family studies. Obes Facts 2009; 2(3):196-202.
18. Littvay L, Métneki J, Tárnoki AD, Tárnoki DL. The Hungarian Twin Registry. Twin Res Hum Genet. 2013; 16(1):185-189.

19. Heath AC, Nyholt DR, Neuman R, Madden PA, Bucholz KK, Todd RD, Nelson EC, Montgomery GW, Martin NG. Zygosity diagnosis in the absence of genotypic data: an approach using latent class analysis. Twin Res 2003; 6(1):22-26. 20. Bosy-Westphal A, Later W, Hitze B, Sato T, Kossel E, Gluer CC, Heller M, Muller MJ. Accuracy of bioelectrical impedance consumer devices for measurement of body composition in comparison to whole body magnetic resonance imaging and dual X-ray absorptiometry. Obes Facts 2008; 1(6):319-324.

21. Scott LJ, Mohlke KL, Bonnycastle LL, Willer CJ, Li Y, Duren WL, Erdos MR, Stringham HM, Chines PS, Jackson AU, ProkuninaOlsson L, Ding CJ, Swift AJ, Narisu N, Hu T, Pruim R, Xiao R, Li XY, Conneely KN, Riebow NL, Sprau AG, Tong M, White PP, Hetrick KN, Barnhart MW, Bark CW, Goldstein JL, Watkins L, Xiang F, Saramies J, Buchanan TA, Watanabe RM, Valle TT, Kinnunen L, Abecasis GR, Pugh EW, Doheny KF, Bergman RN, Tuomilehto J, Collins FS, Boehnke M. A genome-wide association study of type 2 diabetes in Finns detects multiple susceptibility variants. Science 2007; 316(5829):1341-1345.

22. Calle EE, Rodriguez C, Walker-Thurmond $\mathrm{K}$, Thun MJ. Overweight, obesity, and mortality from cancer in a prospectively studied cohort of U.S. adults. N Engl J Med 2003; 348(17):16251638.

23. Kannel WB, Cupples LA, Ramaswami R, Stokes J 3rd, Kreger BE, Higgins M. Regional obesity and risk of cardiovascular disease; the Framingham Study. J Clin Epidemiol 1991; 44(2):183-190.

24. Haslam DW, James WP. Obesity. Lancet 2005; 366(9492):1197-1209.

25. Stefan N, Kantartzis K, Machann J, Schick F, Thamer C, Rittig K, Balletshofer B, Machicao F, Fritsche A, Häring HU. Identification and characterization of metabolically benign obesity in humans. Arch Intern Med 2008; 168(15):16091616.

26. Khan UI, Wang D, Thurston RC, Sowers M, Sutton-Tyrrell K, Matthews KA, Barinas-Mitchell E, Wildman RP. Burden of subclinical cardiovascular disease in "metabolically benign" and "at-risk" overweight and obese women: the Study of Women's Health Across the Nation (SWAN). Atherosclerosis 2011; 217(1):179-186. 
